\title{
Child anxiety and the processing and ambiguity
}

Article

Accepted Version

Dodd, H. F., Stuijfzand, S., Morris, T. and Hudson, J. L. (2015) Child anxiety and the processing and ambiguity. Cognitive Therapy and Research, 39 (5). pp. 669-677. ISSN 0147-5916 doi: https://doi.org/10.1007/s10608-015-9689-1 Available at https://centaur.reading.ac.uk/40176/

It is advisable to refer to the publisher's version if you intend to cite from the work. See Guidance on citing.

Published version at: http://link.springer.com/article/10.1007/s10608-015-9689-1

To link to this article DOI: http://dx.doi.org/10.1007/s10608-015-9689-1

Publisher: Springer

All outputs in CentAUR are protected by Intellectual Property Rights law, including copyright law. Copyright and IPR is retained by the creators or other copyright holders. Terms and conditions for use of this material are defined in the End User Agreement.

\section{www.reading.ac.uk/centaur}

\section{CentAUR}

Central Archive at the University of Reading

Reading's research outputs online 
This is the author's own copy of the following paper:

Child anxiety and the processing of ambiguity

Helen F. Dodd ${ }^{1,2}$, Suzannah Stuijfzand ${ }^{1}$, Talia Morris ${ }^{3}$, \& Jennifer L. Hudson ${ }^{3}$.

${ }^{1}$ School of Psychology and Clinical Language Sciences, University of Reading, Reading, UK

${ }^{2}$ Department of Psychology, Macquarie University, Sydney, Australia

${ }^{3}$ Centre for Emotional Health, Department of Psychology, Macquarie University, Sydney, Australia

The final publication is available at Springer via: http://link.springer.com/article/10.1007/s10608-015-9689-1

\section{Contact details}

Corresponding author: Helen F Dodd

Email: h.f.dodd@reading.ac.uk

Mailing address: School of Psychology and Clinical Language Sciences, Harry Pitt Building, Earley Gate, University of Reading, Whiteknights Road, Reading, RG6 6AL.

Phone: +44 (0)118 3785285

Fax: +44 (0)118 3786715

\section{Acknowledgements}

Thanks to Emily Ramsay, Margie Brammall, Veronica Engel' Kerrie Lam and Amy He for their help with initial data collection and Catia Malvaso for her assistance with reliability coding. Thank you also to the families who so generously give their time to support research. 


\begin{abstract}
An association between interpretation of ambiguity and anxiety may exist in children, but findings have been equivocal. The present research utilized the Interpretation Generation Questionnaire for Children (IGQ-C), a novel measure that breaks down the processing of ambiguity into a three steps: the generation of possible interpretations, the selection of the most likely interpretation and the anticipated emotional response to the ambiguous situation. The IGQ-C was completed by 103 children aged 11-12 years, 28 of whom had a clinical anxiety disorder. There was some evidence for an association between anxiety and: i) the generation of initial negative interpretations; ii) the generation of a greater number of negative interpretations overall; and iii) the selection of negative responses. These findings were not consistent across measures of anxiety. A more convincing association was found between child anxiety and anticipated emotional response to the ambiguous scenarios, with anxious children anticipating more negative emotion.
\end{abstract}

Keywords: Children; anxiety; ambiguity; interpretation; cognitive bias; reappraisal 


\section{Introduction}

Biased interpretation of ambiguity has been hypothesized as a dysfunctional cognition underpinning anxiety disorders (e.g., Beck, Emery, \& Greenberg, 1985; Eysenck, 1992; Williams, Watts, MacLeod, \& Mathews, 1997). This refers to the tendency for an anxious individual to be biased to interpret ambiguity in a negative or threat-related way. There is quite consistent evidence for a negative interpretation bias in anxious adults (e.g. Butler \& Matthews, 1993; Eysenck, Mogg, May, Richards, \& Matthews, 1991) as well as some evidence for this bias in children but findings are less consistent (e.g. Barrett, Rapee, Dadds \& Ryan, 1996; Chorpita, Albano, \& Barlow, 1996; Hadwin, Frost, French \& Richards, 1997; Creswell \& O’Connor, 2011; Creswell, Shildrick and Field, 2011; Creswell, Murray, \& Cooper, 2014).

A common method of assessing interpretation bias in children is to present participants with ambiguous scenarios and ask them to indicate what they would think was happening if they were in that situation. Participants are typically asked to: i) select one interpretation from a number of options; or ii) provide one interpretation that they generate themselves. Although this approach has proved useful, both of these response formats are a poor reflection of how children reason in reality. First, children are not provided with a list of possible alternatives when they are faced with ambiguity in day-to-day life. Second, the cognitive developmental literature suggests that whist children aged 3-4 years tend to provide only one possible alternative in ambiguous situations, older children, certainly by age 12 , identify multiple possible alternatives and recognise that each of these alternatives has a different non-zero probability (Horobin \& Acredolo, 1989). A recent study has shown that even children as young as six years generate multiple interpretations to real-life scenarios (Berry \& Cooper, 2012). Thus, to more accurately capture the process of interpretation in 
older children and adults, a paradigm that allows for the generation of multiple interpretations is required.

To our knowledge, only one small study has examined interpretation bias in child anxiety using a task that allows for the generation of multiple responses. Chorpita et al. (1996) presented 14 participants with ambiguous scenarios and asked them to provide as many interpretations as came to mind (interpretation generation). A significant correlation between trait anxiety and negative interpretations was found, with more anxious children generating more negative interpretations. These authors also asked children to select, from the interpretations they had generated, which they thought was most likely (interpretation selection). Children with higher levels of anxiety were more likely to select negative interpretations.

This distinction between interpretation generation and interpretation selection is consistent with information-processing models. Crick and Dodge (1994) propose a series of processing stages that children engage in when they process social cues, beginning with the encoding of external and internal cues. This is followed by an interpretation phase, when children draw on their existing knowledge to formulate possible interpretations of the event. It is specifically highlighted that interpretation can incorporate a number of distinct processes. A series of processing stages then follow including goal selection, construction of possible responses and selection of a response before the chosen behavior is enacted.

When considering the processing stages that children might engage in when faced with ambiguous stimuli, the cognitive reappraisal literature also provides some useful insights. Cognitive reappraisal is an emotion regulation strategy that involves changing ones interpretations of affective stimuli by considering alternative appraisals (or interpretations) of a situation. Neuroimaging research has shown that engaging in reappraisal activates regions involved in cognitive control, including dorsomedial prefrontal cortex (dmPFC), dorsolateral 
prefrontal cortext (dlPFC), ventrolateral prefrontal cortext (vlPFC) and posterior parietal lobe and further, that reappraisal modulates activity in bilateral amygdala, which is strongly linked with emotional responding (Buhle et al., 2013). This highlights that a distinction can be made between the cognitive interpretation phase and the individual's emotional response.

Research focused on interpretation bias in child anxiety is increasingly recognizing the importance of studying children's emotional responses to ambiguity as well as their actual interpretations when they are presented with ambiguous scenarios. For example, Waters and colleagues (Waters, Craske, Bergman, \& Treanor, 2008) found that anxious children expected more negative emotion in ambiguous situations than control participants or children of anxious parents. Similarly, Waters, Wharton, Zimmer-Gembeck and Craske (2008) found a relationship between anxiety and anticipated negative emotion in response to ambiguous scenarios. Furthermore, a recent longitudinal study reported consistently strong associations between anticipated negative emotion in response to ambiguous scenarios and anxiety in both cross-sectional and longitudinal analyses (Creswell \& O'Connor, 2011). This suggests that consideration of how children anticipate they will feel when faced with ambiguous situations, as well as how they interpret them, might be important for understanding the nature of children's anxiety. Thus, in the present research, we distinguish between three phases of children's responding to ambiguous stimuli: interpretation generation, interpretation selection and emotional response.

A final issue in the investigation of interpretation bias in child anxiety is the extent to which bias is related to anxiety specifically, rather than driven by an association with comorbid symptoms of depression; depressed adults also show a negative interpretation bias and there is some indication that this bias may also be associated with depression in youth (Dearing \& Gotlib, 2009; Lau, Molyneaux, Telman \& Belli, 2011; Lothmann, Holmes, Chan \& Lau, 2010). A number of studies that have examined interpretation bias in child anxiety 
have included an assessment of depression. In general, the results suggest that the association between anxiety and interpretation bias is not driven by comorbid symptoms of depression but this remains an important consideration.

\section{Aims and hypotheses}

The present research had two principle aims. First, to more closely investigate the nature of interpretation bias in anxious children by examining interpretation generation and selection. Second, to examine the association between anxiety and anticipated emotional response to ambiguity. This research contributes to the literature on interpretation bias in child anxiety by breaking down the processing of ambiguity to gain insight into the specific ways in which anxious children differ from non-anxious children. It was hypothesized that anxiety would be associated with: 1) the generation of more negative interpretations to ambiguous scenarios; 2) the selection of more negative interpretations to ambiguous scenarios; and 3) the anticipation of more negative emotion when faced with an ambiguous scenario. Given the comorbidity between anxiety and depression, the association between symptoms of depression and responses to the ambiguous situations was also examined.

\section{Method}

\section{Participants}

Participants were 103 children (39 boys) aged 10 to 12 years (Mean age $=11.17$, SD $=0.45)$. An additional two participants consented to take part but did not complete the task correctly, so were excluded. All participants were taking part of a larger longitudinal study designed to examine predictors of emotional health problems in children (Hudson, Dodd \& Bovopoulos, 2011) and had participated in our previous research examining interpretation bias in preschool-aged children (Dodd, Hudson, Morris and Wise, 2012). Participants were originally recruited when they were aged between 3 years 2 months and 4 years 5 months. At 
this time, children scoring more than one standard deviation above or less than one standard deviation below the normative mean on the Approach Scale of the Short Temperament Scale for Children (STSC; Sanson, Smart, Prior, Oberklaid, \& Pedlow, 1994) were classified as behaviourally inhibited (BI) or behaviourally uninhibited (BUI) respectively.

The present study was conducted as part of the 8-year follow-up of this longitudinal sample. Approximately 140 (69\%) of the original participants were invited to take part in the present research giving a participation rate of $74 \%$. Of the participants in the present sample, 64 had originally been classified as BI (38\%) and BUI (62\%). The current sample was primarily made up of Oceanic (67\%), Asian (8.9\%), and European (20\%) ethnicities. Family income data were provided by 77 participants. Of those that responded $73 \%$ were from middle to high income families (annual income of $\$ 80,000$ or more). All parent-report measures detailed below were completed by mothers. Of those who provided information (>95\% of participants for each variable), all identified as being the child's biological parent, $86 \%$ were married, $17 \%$ met criteria for an anxiety disorder themselves and the mean maternal age was 44 years $(\mathrm{SD}=4.4$ years).

\section{Measures}

Interpretation Generation Questionnaire Child (IGQ-C). A measure was created for the present study to assess participants' generation, selection and anticipated emotional response to ambiguous scenarios (measure available from the corresponding author). The measure is an adaptation and modification of the ambiguous scenarios methodology used in previous studies (Barrett et al., 1996; Wisco and Nolen-Hoeskma, 2010) and includes 12 vignettes that describe ambiguous everyday situations. To ensure that the scenarios draw upon a range of situations, six are social (e.g. "You're giving a speech. People in the audience start laughing. Why?") and six are non-social (e.g. "Your stomach starts to feel a bit 
funny during the morning at school, why?"). To check that the scenarios were ambiguous, twelve adult volunteers rated the positivity/negativity of the scenarios on a 7-point Likert scale ranging from "very bad" (-3) to "very good" (3). The mean rating for the scenarios included was $-0.19(\mathrm{SD}=0.56)$ indicating that the scenarios were ambiguous.

The response format was based on the measure in Wisco and Nolen-Hoeskma (2010). Participants were instructed to imagine that each scenario was happening to them and then to write down all the explanations that came to mind (interpretation generation). The questionnaire allowed a maximum of ten interpretations for each scenario. Participants were then instructed to select, from their interpretations, the one they would think was "most likely" if they were in the situation (interpretation selection). Finally, anticipated emotional response to the ambiguous situation was assessed by asking participants to rate how it would make them feel if this situation was actually happening to them, using a Likert scale from ranging from -3 (very bad) to 3 (very good).

Coding Responses. Participant interpretations were coded individually as negative, or not negative, using a coding scheme developed for the purposes of this research (coding manual available from the corresponding author). "Negative" was operationalised as being any interpretation that suggested a negative outcome for the participant or reflected negative attributions about the self. A minority of the participants missed one $(\mathrm{N}=9)$ or two scenarios $(\mathrm{N}=1)$ but all participants had complete data for at least 10 of the scenarios. To ensure that all participants' data could be used and that the variables were comparable across participants, the following variables were calculated: proportion of initial interpretations that were negative (total number of initial interpretations that were negative divided by the total number of scenarios completed); proportion of interpretations that were negative (total number of responses that were negative divided by the total number of interpretations made); proportion of selected interpretations that were negative (total number of selected 
interpretations that were negative divided by the number of scenarios completed); and average emotional response rating (sum of emotional response ratings divided by the number of scenarios for which an emotional response rating was made).

Responses were coded by a psychology masters student who was blind to participant anxiety level or clinical status. To ensure reliability, $23 \%$ of responses, selected at random, were second coded by a research intern. Inter-rater reliability ranged from $\operatorname{ICC}(2,1)=.83$ .93 for the above variables. Internal consistency was good for the total number of interpretations that were negative $(\alpha=.78)$ and for emotional response rating ( $\alpha=.76)$, but was lower for scales comprised from binary variables (selected responses: $\alpha=.52$; initial responses: $\alpha=.46$ ). These are reasonably comparable with other interpretation bias scales derived from binary data (e.g. Creswell, Cooper and Murray, 2014 reported alphas ranging from $0.56-0.79)$ and results are interpreted with this in mind.

Spence Children's Anxiety Scale. The self-report version and parent report versions of the Spence Children's Anxiety Scale (SCAS - Spence, 1998; SCAS-P - Nauta, Scholing, Rapee, Abbott, Spence and Waters, 2004) were used to assess the severity of anxiety symptoms. Both versions include 38 items that ask about a range of anxiety symptoms. The parent-report measure was developed to correspond as closely as possible to the child version. For both scales, items are rated on a 4-point Likert scale, giving a range of scores from 0 to 114 (see www.scaswebsite.com for more information). In the present study, internal consistency was excellent $\alpha=.91$ for the SCAS and $\alpha=.91$ for the SCAS-P.

Short Mood and Feelings questionnaire. The self-report (SMFQ) and parent-report (SMFQ-P) versions of the Short Mood and Feelings Questionnaire (Angold, Costello, Messer, Pickles, Winder, \& Silver, 1995) were used to measure symptoms of depression. The parent and child versions of the scale correspond closely and both include 11 items. The participant is asked to rate whether a specific phrase (e.g. 'I (s/he) felt miserable or unhappy') 
is indicative of their/their child's feelings and behaviour using a three point likert scale (0-2). In the present sample the internal consistency was good for child self-report; Cronbach's $\alpha=$ .86 , and for parent-report; Cronbach's alpha $=.88$.

Anxiety Disorders Interview Schedule for Children (ADIS-C/P). The ADIS-C/P (Silverman \& Albano, 1996) is a psychometrically sound semi-structured interview that provides extensive coverage of anxiety disorders. Child participants and their mothers were interviewed about the child's anxiety and diagnoses and Clinical Severity Ratings (CSRs on a scale of 0-8) were then assigned by a clinical researcher who had been extensively trained and was supervised by an experienced clinical psychologist. Diagnoses were based on the criteria set out by the DSM-IV (American Psychiatric Association, 1994) and were only considered clinical if the CSR was four or greater.

On the basis of the ADIS interviews, 28 children met criteria for a clinical anxiety disorder and 75 children did not. These groups will be referred to as clinically anxious children (ANX) and non-anxious children (NANX). In total, the anxious children met criteria for 56 anxiety diagnoses, an average of two per child. The most common diagnoses were Social Anxiety Disorder ( $\mathrm{N}=16)$, Generalised Anxiety Disorder $(\mathrm{N}=14)$ and Specific Phobia $(\mathrm{N}=20)$. A total of $30 \%$ of interviews were coded by a second clinician from videotape. Interrater agreement for the presence of a current anxiety diagnosis was excellent (kappa $=0.92)$.

\section{Procedure}

Macquarie University Human Ethics Committee approved the methods of the study. A letter explaining the research and a consent form were sent by mail to parents. Parents were then contacted by phone to seek consent and to arrange participation. Parents and children visited the university for a 2-hour session during which all ADIS interviews and IGQ-C outlined above were completed, along with other assessments for the longitudinal study. 
After being given a description of the study, mothers provided written informed consent for themselves and their children and the children provided assent to the study procedures after being told what each phase of the research would involve.

Children completed the IGQ-C on a computer, supervised by postgraduate psychology students. The measure was self-paced, and participants were instructed to write as many explanations as came to mind for each vignette. Participants were also given the option of having the assistant type their answers for them if they were not confident typing. At the end of each vignette the participant was prompted "Is that as many as you can think of?" Once they pressed the "Next Question" the next scenario was presented. The scenarios were presented in a random order. Participants completed the IGQ-C whilst their mother completed the ADIS-P interview. Upon completion, the child completed their ADIS interview. The questionnaires were all completed online prior to the assessment session. Families were reimbursed AU $\$ 50$ for participation.

\section{Results}

The ICQ-C yielded four continuous variables: proportion of initial interpretations that were negative; proportion of interpretations that were negative; proportion of selected interpretations that were negative; average emotional response rating. Demographic variables collected were gender, ethnicity, child age, and annual gross family income. Preliminary analyses indicated that the demographic variables were not significantly related to scores on the SCAS, SMFQ or ICQ-C ( $p>.05)$, with the exception of family income, which was positively associated with emotional response ratings and negatively associated with both SCAS and SMFQ total score. Similarly, no differences between clinically anxious children and non-anxious children were found for any of the demographic variables ( $p>.05)$ except for family income, with children from lower income families more likely to meet criteria for an 
anxiety diagnosis. No significant differences between BI groups were found for any of the IGQ-C variables $(p>.05)$.

ADIS diagnostic data was available for all participants but some failed to complete all of the other measures (maximum number of participants missing data on any measure $=10$ ). Participants were excluded from analyses if they were missing relevant data for that analysis. There was no difference between participants with complete data and those with missing data on age, gender, ethnicity, family income or clinical anxiety status $(p>.1)$. Means and standard deviations for the questionnaire measures are shown in Table 1.

The following variables were positively skewed: proportion of initial responses that were negative, proportion of selected interpretations that were negative, SCAS total score. SCAS-P total score, SMFQ total score; SMFQ-P total score. All analyses involving these variables were therefore bootstrapped and bootstrapped estimates, using 1000 bootstrapped samples, are reported.

To first check for anxiety-related differences in how the ICQ-C was completed, some preliminary analyses were conducted. Initially, the average number of responses generated across scenarios was examined in relation to anxiety and depression. No significant association was found between average number of responses generated overall and SCAS, SCAS-P, SMFQ or SMFQ-P scores $(p>.05)$ and there was no significant difference between anxiety groups, $(\mathrm{ANX}(\mathrm{M}=3.57(\mathrm{SD}=1.07)$; $\mathrm{NANX} \mathrm{M}=3.8(\mathrm{SD}=1.33)), \mathrm{t}(101)=.80, p=$ 42. In addition, we examined the proportion of trials in which the first interpretation given was the one selected; this was not significantly associated with SCAS, SCAS-P, SMFQ or SMFQ-P score $(p>.05)$, and there was no significant difference between anxiety groups $(\mathrm{ANX} \mathrm{M}=49.7 \% ; \mathrm{SD}=18.58) ; \mathrm{NANX} \mathrm{M}=48.9 \% ; \mathrm{SD}=20.4), \mathrm{t}(101)=.19, p=.85$

\section{Hypothesis testing}


For each hypothesis, two types of analysis were conducted; point-biserial correlations were conducted to examine the association between IGQ-C variables and an anxiety disorder diagnosis and bivariate correlations were conducted to examine the association between IGQC variables and anxiety symptoms, as measured on the SCAS and SCAS-P. Bivariate correlations were also conducted to examine the association between IGQ-C variables and depressive symptoms, as measured on the SMFQ and SMFQ-P. Table 2 shows the results of the point-biserial correlations. This data is also displayed in Figure 1. The bivariate correlation results are displayed in Table 3. The association between emotional response rating and anxiety/depression is shown in Figure 2.

\section{Discussion}

The first aim of the present research was to investigate the nature of interpretation bias in anxious children by examining interpretation generation and selection. It was first hypothesized that anxiety would be positively associated with the generation of more negative interpretations to ambiguous scenarios. The results provided some support for this hypothesis; children with higher self-rated anxiety symptoms were more likely to provide an initial interpretation that was negative and to generate more negative interpretations overall. However, no significant relation was found between generation of negative interpretations and the presence of a clinical anxiety diagnosis or parent-report of child anxiety. It was further hypothesized that anxiety would be associated with the selection of more negative interpretations to ambiguous scenarios. Again, this hypothesis was partially supported; a significant association was found between selection of negative interpretations and the presence of a clinical anxiety diagnosis, but no significant association was found with anxiety symptoms. 
Taken together, the results provide some indication of subtle associations between anxiety and interpretation generation and selection, but the effects are small and inconsistent across anxiety measures. This inconsistency may reflect genuine differences between children with an anxiety disorder and those with high anxiety symptoms; perhaps settling upon a negative interpretation as most likely is a unique characteristic of clinical anxiety. Alternatively, the inconsistency may indicate that the association between anxiety and the negative interpretation of ambiguity, using the IGQ-C is relatively weak. This is contrary to our hypotheses but previous findings in the child literature have been equivocal, with several other studies also reporting no association, or inconsistent associations, between interpretation bias and anxiety in children. For example, Creswell et al. (2014) found no differences in interpretations of ambiguous situations between clinically anxious and control participants and Creswell and O'Connor (2011) failed to find a consistent relation between interpretation bias and anxiety symptoms.

The second aim was to examine the relation between anxiety and anticipated emotional response to ambiguity. It was hypothesized that anxiety would be associated with the anticipation of more negative emotion in response to ambiguous scenarios. This hypothesis received the clearest support; participants with higher self-rated anxiety symptoms had more negative emotional response ratings and there was a significant association with clinical anxiety, such that clinically anxious children anticipated more negative emotion in response to the ambiguous scenarios.

The information-processing model proposes a series of processing stages that children engage in when faced with ambiguity (Crick \& Dodge, 1994). Drawing upon this approach and the cognitive reappraisal literature, we examined three phases of children's responding to ambiguity: interpretation generation (broken down into initial interpretation and subsequent interpretations), interpretation selection and emotional response. The correlations between 
these phases were significant, as would be expected for a related sequence of events. Notably, the highest correlations were found between processing stages one would anticipate would be adjacent (initial interpretation - overall interpretation generation - interpretation selection emotional response). There was no indication that children with anxiety disorders had more difficulty generating interpretations overall and little evidence that the interpretations generated by children higher in anxiety were more negative. This suggests that children with anxiety disorders may not have difficulty generating alternative interpretations, as required for cognitive reappraisal, when they are prompted to do so. However, children who are anxious may spontaneously engage in reappraisal less frequently than those who are not anxious (Carthy, Horesh, Apter, Edge, \& Gross, 2010). Thus, anxious children may not have a skill deficit but anxious children may not apply this skill spontaneously.

A clearer association was found between child anxiety and anticipated emotional response. This is consistent with other recent findings (Creswell \& O'Connor, 2011; Waters, Craske et al., 2008; Waters, Whorton et al., 2008). The clinically anxious children anticipated more negative emotion in comparison to the controls even though their interpretations were similar, indicating that the interpretations were not driving the emotional response entirely. Clearly, further investigation into the mechanisms underpinning this emotional response is required; in the present study, we intentionally kept the emotional response question broad in order to measure overall affective reaction, but further insight into this affective response could be gleaned by asking more specific questions. For example, children's cognitions about their ability to cope with the situation, the extent to which they would worry about the situation and their distress regarding the uncertainty of the situation would all be useful questions for future research. Furthermore, linking these findings with anxiety-linked individual differences in the activation of brain regions involved in cognitive control and emotion (e.g. Cisler, Olatunji, Felder \& Forsyth, 2010; Goldin, Manber, Hakimi, Canli, \& 
Gross, 2009; Goldin, Ball, Werner, Heimberg \& Gross, 2010) may prove a fruitful avenue for future work.

There are some points for consideration that should be highlighted. First, there was little indication that any associations between anxiety and responses on the IGQ-C were driven by comorbid symptoms of depression. Second, parent-report of child anxiety was not associated with any of the IGQ-C outcome measures, including anticipated emotional response. This is perhaps not surprising as agreement between parent and child indices of anxiety is often poor (Comer \& Kendall, 2004; Salbach-Andrae, Lenz \& Lehmkuhl, 2009). A third consideration is that the IGQ-C had good internal consistency for two scales, but two scales had relatively poor internal consistency. Further evaluation of the psychometric properties of this scale is therefore required. Finally, the sample were not treatment seeking. It would be informative for research to use the IGQ-C before and after treatment of anxiety disorders to ascertain first, whether a clinic-based sample show the same biases, and second how children's responses to ambiguity change across treatment and how these changes are linked to symptom change. Work of this nature would provide additional insights that could further inform our approach to treating anxiety disorders in children.

\section{$\underline{\text { Disclosures }}$}

Conflict of Interest: Helen Dodd, Jennifer Hudson, Suzannah Stuijfzand and Talia Morris declare that they have no conflict of interest. This project was supported by funding from the Australian Research Council (DP1095162, DP0878609) to Jennifer Hudson. The data have not been presented or published previously. Macquarie University Human Ethics Committee approved the methods of the study and all procedures performed in this study were in accordance with the ethical standards Macquarie University Human Research Ethics Committee and with the 1964 Helsinki declaration and its later amendments. Parents provided informed consent on behalf of their children and children provided verbal assent 
after the study procedures had been explained to them. No animal studies were carried out by the authors for this paper.

\section{References}

American Psychiatric Association. (1994). Diagnostic and statistical manual of mental disorders (4th ed.). American Psychiatric Association: Washington, DC.

Angold, A., Costello, E. J., Messer, S. C., Pickles, A., Winder, F., \& Silver, D. (1995) The development of a short questionnaire for use in epidemiological studies of depression in children and adolescents. International Journal of Methods in Psychiatric Research, 5, 237 - 249.

Barrett, P. M., Rapee, R. M., Dadds, M. R., \& Ryan, S. M. (1996). Family enhancement of cognitive style in anxious and aggressive children. Journal of Abnormal Child Psychology, 24, 187-203. doi: 10.1007/BF01441484

Beck, A. T., Emery, G., \& Greenberg, R. L. (1985). Anxiety disorders and phobias: a cognitive perspective. Basic Books: New York.

Berry, A., \& Cooper, M. (2012). Anxious children's ability to generate alternative attributions for ambiguous situations. Behavioural and Cognitive Psychotherapy, 40, 89-103. doi: 10.1017/S1352465811000518

Buhle, J.T., Silvers, J.A., Wager, T.D., Lopez, R., Onyemekwu, C., Kober, H., Weber, J., \& Ochsner, K.N. (2014). Cognitive reappraisal of emotion: a meta-analysis of human neuroimaging studies. Cerebral Cortex, 24, 2981-2990. doi: 10.1093/cercor/bht154

Butler, G., \& Matthews, A. (1983). Cognitive processes in anxiety. Advances in Behaviour Research and Therapy, 5, 51-62. doi: 10.1016/0146-6402(83)90015-2

Carthy, T., Horesh, N., Apter, A., Edge, M.D., Gross, J.J. (2010). Emotional reactivity and cognitive regulation in anxious children. Behaviour Research and Therapy, 48 (5), 384-393. doi: 10.1016/j.brat.2009.12.013 
Chorpita, B.F., Albano, A.M., \& Barlow, D.H. (1996). Cognitive processing in children: Relationship to anxiety and family influences. Journal of Clinical Child Psychology, 25, 170-176. doi: 10.1207/s15374424jccp2502_5

Cisler, J. M., Olatunji, B. O., Feldner, M. T., \& Forsyth, J. P. (2010). Emotion Regulation and the Anxiety Disorders: An Integrative Review. Journal of Psychopathology and Behavioral Assessment, 32(1), 68-82. doi:10.1007/s10862-009-9161-1

Comer, J. S., \& Kendall, P. C. (2004). A symptom-level examination of parent-child agreement in the diagnosis of anxious youths. Journal of the American Academy of Child \& Adolescent Psychiatry, 43(7), 878-886. doi: 10.1097/01.chi.0000125092.35109.c5

Creswell, C. and O'Connor, T. G. (2011) Interpretation bias and anxiety in childhood: stability, specificity and longitudinal associations. Behavioural and Cognitive Psychotherapy, 39 (02), 191-204. doi: 10.1017/S1352465810000494

Creswell, C., Shildrick, S. and Field, A. P. (2011) Interpretation of ambiguity in children: a prospective study of associations with anxiety and parental interpretations. Journal of Child and Family Studies, 20 (2), 240-250. doi: 10.1007/s10826-010-9390-7

Creswell, C., Murray, L. and Cooper, P. (2014) Interpretation and expectation in childhood anxiety disorders: age effects and social specificity. Journal of Abnormal Child Psychology, 42 (3), 453-465. doi: 10.1007/s10802-013-9795-z

Crick, N.R., \& Dodge, K.A. (1994). A review and reformulation of social informationprocessing mechanisms in children's social adjustment. Psychological Bulletin, 115(1), 74-101. doi: 10.1037/0033-2909.115.1.74

Dearing, K. F., \& Gotlib, I. H. (2009). Interpretation of Ambiguous Information in Girls at Risk for Depression. Journal of Abnormal Child Psychology, 37(1), 79-91. doi:10.1007/s10802-008-9259-Z

Dodd, H.F., Hudson, J.L., Morris, T., \& Wise, C. (2012). Interpretation bias is preschool children at risk for anxiety: a prospective study. Journal of Abnormal Psychology, 121 (1), 28-38. doi: 10.1037/a0024589 
Eysenck, M. W. (1992). Anxiety: the cognitive perspective. Lawrence Erlbaum Associated Ltd. UK.

Eysenck, M.W., Mogg, K., May, R., Richards, A., \& Mathews, A. (1991). Bias in interpretation of ambiguous sentences related to threat in anxiety. Journal of Abnormal Psychology, 100, 144-150. doi: 10.1037/0021-843X.100.2.144

Goldin, P.R., Manber, T., Hakimi, S., Canli, T., Gross, J.J. (2009). Neural Bases of Social Anxiety Disorder: Emotional Reactivity and Cognitive Regulation During Social and Physical Threat. Archives of General Psychiatry, 66 (2), 170-180. doi:10.1001/archgenpsychiatry.2008.525.

Goldin, P. R., Ball, T. M., Werner, K., Heimberg, R., \& Gross, J. J. (2009). Neural Mechanisms of Cognitive Reappraisal of Negative Self-Beliefs in Social Anxiety Disorder. Biological Psychiatry, 66 (12), 1091-1099. doi:10.1016/j.biopsych.2009.07.014

Hadwin, J., Frost, S., French, C. C., \& Richards, A. (1997). Cognitive processing and trait anxiety in typically developing children: evidence for an interpretation bias. Journal of Abnormal Psychology, 106, 486-490. doi: 10.1037/0021-843X.106.3.486

Horobin, K., \& Acredolo, C. (1989). The Impact of Probability Judgments on Reasoning about Multiple Possibilities. Child Development, 60 (1), 183-200. doi: $10.2307 / 1131084$

Hudson, J. L., Dodd, H. F., \& Bovopoulos, N. (2011). Temperament, family environment and anxiety in preschool children. Journal of Abnormal Child Psychology, 39 (7), 939951. doi: 10.1007/s10802-011-9502-x

James, A., Soler, A., \& Weatherall, R. (2005). Cognitive behavioural therapy for anxiety disorders in children and adolescents. Cochrane Database Systematic Reviews, 4, 126. doi: 10.1002/14651858.CD004690.pub2

Lau, J.Y.F. Molyneaux, E., Telman, M. \& Belli, S. (2011). The Plasticity of Adolescent Cognitions: Data from a Novel Cognitive Bias Modification Training Task. Child Psychiatry \& Human Development, 42 (6), 679-693. Doi: 10.1007/s10578-011-02443 
Lothmann, C., Holmes, E.A., Chan, S.W.Y., \& Lau, J.Y.F. (2011). Cognitive bias modification training in adolescents: effects on interpretation biases and mood. Journal of Child Psychology and Psychiatry, 52 (1), 24-32. doi: 10.1111/j.14697610.2010.02286.x

Nauta, M. H., Scholing, A., Rapee, R. M., Spence, S. H., \& Waters, A. (2004). A parentreport measure of children's anxiety: Psychometric properties and comparison with child-report in a clinic and normal sample. Behaviour Research and Therapy, 42, 813839. doi: 10.1016/S0005-7967(03)00200-6

Salbach-Andrae, H., Lenz, K., \& Lehmkuhl, U. (2009). Patterns of agreement among parent, teacher and youth ratings in a referred sample. European Psychiatry, 24 (5), 345-351. doi: 10.1016/j.eurpsy.2008.07.008

Sanson, A., Smart, D., Prior, M., Oberklaid, F., \& Pedlow, R. (1994). The structure of temperament from age 3 to 7 years: Age, sex, and sociodemographic influences. Merrill-Palmer Quarterly, 40, 233-252.

Silverman, W. K., \& Albano, A. M. (1996). The Anxiety Disorders Interview Schedule for Children for DSM-IV: Child and Parent Versions. San Antonia, TX: Psychological Corporation.

Spence, S. H. (1998). A measure of anxiety symptoms among children. Behavioural Research and Therapy, 36, 545-566. doi: 10.1016/S0005-7967(98)00034-5

Waters, A. M., Craske, M. G., Bergman, R. L., \& Treanor, M. (2008). Threat interpretation bias as a vulnerability factor in childhood anxiety disorders, Behaviour Research \& Therapy. 46(1), 39-47. doi: 10.1016/j.brat.2007.10.002

Waters, A. M., Wharton, T. A., Zimmer-Gembeck, M. J., \& Craske, M. G. (2008). Threatbased cognitive biases in anxious children: Comparison with non-anxious children before and after cognitive-behavioural treatment. Behaviour Research \& Therapy. 46(3), 358-374. doi: 10.1016/j.brat.2008.01.002 
Williams, J.M.G., Watts, P.N., MacLeod, C., \& Mathews, A. (1997). Cognitive psychology and emotional disorders (2nd ed.). Chichester, UK: Wiley.

Wisco, B. E., \& Nolen-Hoeskma, S. (2010). Interpretation bias and depressive symptoms: The role of self-relevance. Behaviour Research and Therapy, 48, 1113-1122. doi: 10.1016/j.brat.2010.08.004 
Table 1

Group means and standard deviations for clinically anxious and non-anxious children on each of the questionnaire measures.

\begin{tabular}{lcccc}
\hline Variable & $\begin{array}{c}\text { Clinically Anxious } \\
\text { children } \\
\mathrm{N}=28\end{array}$ & $\begin{array}{c}\text { Non-anxious } \\
\text { children } \\
\mathrm{N}=75\end{array}$ & $\begin{array}{c}\text { Cohen's } \\
d\end{array}$ & $p$ - value \\
\hline SCAS & $24.12(12.46)$ & $12.6(8.83)$ & $1.04^{* *}$ & $p<.001$ \\
SCAS-P & $21.53(10.21)$ & $9.1(7.66)$ & $1.33^{* *}$ & $p<.001$ \\
SMFQ & $4.04(3.78)$ & $1.81(2.81)$ & $0.64^{*}$ & $p=.003$ \\
SMFQ-P & $4.73(4.64)$ & $1.17(2.14)$ & $1.06^{* *}$ & $p<.001$ \\
\hline$* p<.01 ; * * p<.001$ & & & &
\end{tabular}


Table 2

Group means and standard deviations for clinically anxious and non-anxious children on each of the interpretation bias variables and point biserial correlations.

\begin{tabular}{|c|c|c|c|c|c|}
\hline Stage & Variable & $\begin{array}{l}\text { Clinically } \\
\text { Anxious } \\
\text { children } \\
\mathrm{N}=28\end{array}$ & $\begin{array}{l}\text { Non-anxious } \\
\text { children } \\
\mathrm{N}=75\end{array}$ & $\begin{array}{c}\text { Point- } \\
\text { biserial } \\
\text { correlation }\end{array}$ & $\begin{array}{c}p- \\
\text { value }\end{array}$ \\
\hline $\begin{array}{l}\text { Initial } \\
\text { Interpretation }\end{array}$ & $\begin{array}{l}\text { Proportion of initial } \\
\text { responses that were } \\
\text { negative }\end{array}$ & $.28(.17)$ & $.24(.16)$ & $.12^{\wedge}$ & .22 \\
\hline Generation & $\begin{array}{l}\text { Proportion of } \\
\text { responses generated } \\
\text { that were negative }\end{array}$ & $.30(.13)$ & $.28(.11)$ & .10 & .33 \\
\hline Selection & $\begin{array}{l}\text { Proportion of } \\
\text { selected responses } \\
\text { that were negative }\end{array}$ & $.19(.16)$ & $.13(.13)$ & $.20^{\wedge}$ & $.038 *$ \\
\hline $\begin{array}{l}\text { Emotional } \\
\text { response }\end{array}$ & $\begin{array}{l}\text { Mean emotional } \\
\text { response rating }\end{array}$ & $-.26(.76)$ & $.06(.69)$ & -.20 & $.041 *$ \\
\hline
\end{tabular}


Table 3

Bootstrapped bivariate correlations (and p-values) between SCAS scores, SMFQ scores and IGQ-C variables.

\begin{tabular}{|c|c|c|c|c|c|c|c|c|}
\hline Stage & Variable & $\begin{array}{l}\text { SCAS } \\
\text { total } \\
\text { score }\end{array}$ & $\begin{array}{l}\text { SCAS- } \\
\text { P total } \\
\text { score }\end{array}$ & $\begin{array}{c}\text { SMFQ } \\
\text { total } \\
\text { score }\end{array}$ & $\begin{array}{l}\text { SMFQ- } \\
\text { P total } \\
\text { score }\end{array}$ & $\begin{array}{c}\text { Initial } \\
\text { interpretation }\end{array}$ & Generation & Selection \\
\hline \multirow[t]{3}{*}{-} & SCAS-P & $.58 * *$ & & & & & & \\
\hline & total score & $(p<$ & & & & & & \\
\hline & & $.001)$ & & & & & & \\
\hline \multirow[t]{3}{*}{-} & SMFQ total & $.59 * *$ & $.26^{*}$ & & & & & \\
\hline & score & $(p<$ & $(p=$ & & & & & \\
\hline & & $.001)$ & $.01)$ & & & & & \\
\hline \multirow[t]{3}{*}{-} & SMFQ-P & $.47^{* *}$ & $.41 * *$ & $.42 * *$ & & & & \\
\hline & total score & $(p<$ & $(p<$ & $(p<$ & & & & \\
\hline & & $.001)$ & $.001)$ & $.001)$ & & & & \\
\hline \multirow[t]{3}{*}{$\begin{array}{l}\text { Initial } \\
\text { Interpretation }\end{array}$} & $\begin{array}{l}\text { Proportion } \\
\text { of initial }\end{array}$ & $.23^{*}$ & .07 & .17 & & & & \\
\hline & $\begin{array}{l}\text { responses } \\
\text { that were }\end{array}$ & $(p=$ & $(p=$ & $(p=$ & $(p=$ & & & \\
\hline & negative & $.026)$ & $.48)$ & $.1)$ & $.51)$ & & & \\
\hline Generation & $\begin{array}{l}\text { Proportion } \\
\text { of } \\
\text { responses } \\
\text { generated } \\
\text { that were } \\
\text { negative }\end{array}$ & $\begin{array}{l}.22^{*} \\
(p= \\
.03)\end{array}$ & $\begin{array}{c}.9 \\
(p= \\
.39)\end{array}$ & $\begin{array}{l}.08 \\
(p= \\
.44)\end{array}$ & $\begin{array}{c}.1 \\
(p= \\
.34)\end{array}$ & $\begin{array}{c}.65^{* *} \\
(p<.001)\end{array}$ & & \\
\hline Selection & $\begin{array}{l}\text { Proportion } \\
\text { of selected } \\
\text { responses } \\
\text { that were } \\
\text { negative }\end{array}$ & $\begin{array}{l}.19 \\
(p= \\
.07)\end{array}$ & $\begin{array}{l}.03 \\
(p= \\
.8)\end{array}$ & $\begin{array}{l}.16 \\
(p= \\
.14)\end{array}$ & $\begin{array}{l}.11 \\
(p= \\
.27)\end{array}$ & $\begin{array}{c}.45^{* *} \\
(p<.001)\end{array}$ & $\begin{array}{c}.58^{* *} \\
(p<.001)\end{array}$ & \\
\hline $\begin{array}{l}\text { Emotional } \\
\text { Response }\end{array}$ & $\begin{array}{l}\text { Mean } \\
\text { emotional } \\
\text { response } \\
\text { rating }\end{array}$ & $\begin{array}{c}-.32 * * \\
(p= \\
.001)\end{array}$ & $\begin{array}{l}-.02 \\
(p= \\
.83)\end{array}$ & $\begin{array}{c}-.28 * * \\
(p= \\
.006)\end{array}$ & $\begin{array}{l}-.06 \\
(p= \\
.54)\end{array}$ & $\begin{array}{c}-.32 * * \\
(p=.003)\end{array}$ & $\begin{array}{c}-.32 * * \\
(p=.002)\end{array}$ & $\begin{array}{c}-.64^{* *} \\
(p<.001)\end{array}$ \\
\hline
\end{tabular}



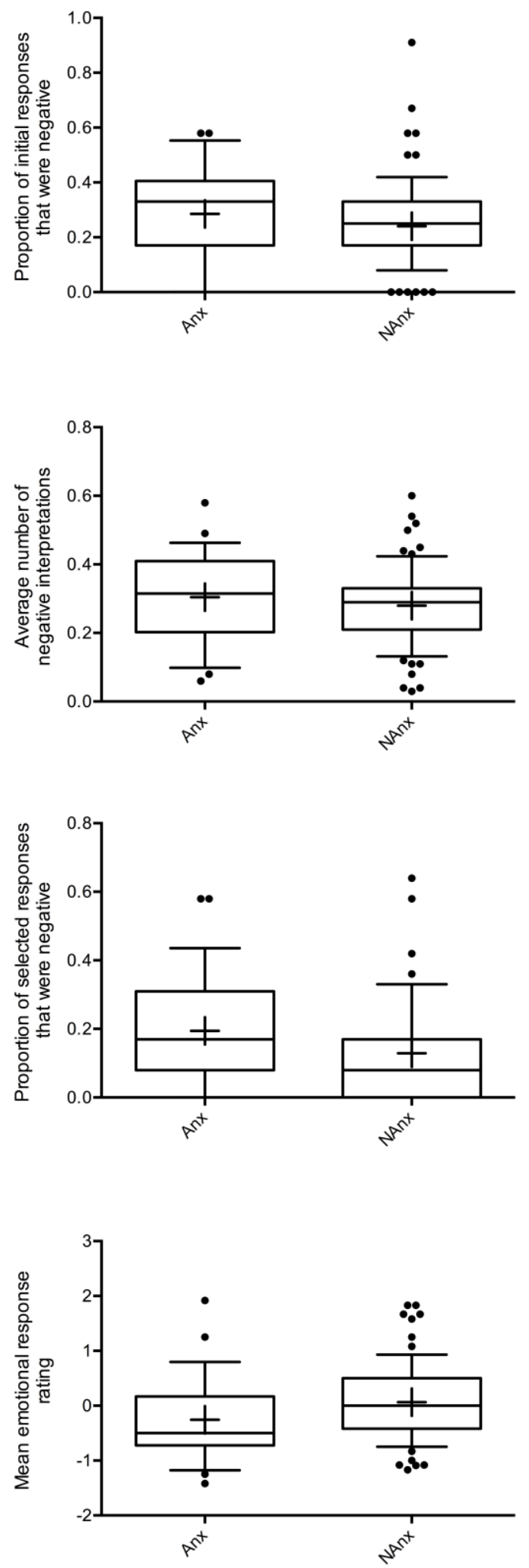

Figure 1. Anxiety group differences on each of the IGQ-C variables. Boxes show $25^{\text {th }}$ to $75^{\text {th }}$ percentiles, with median indicated by horizontal line across box and mean indicated by + , whiskers show $10^{\text {th }}$ to $90^{\text {th }}$ percentiles. 

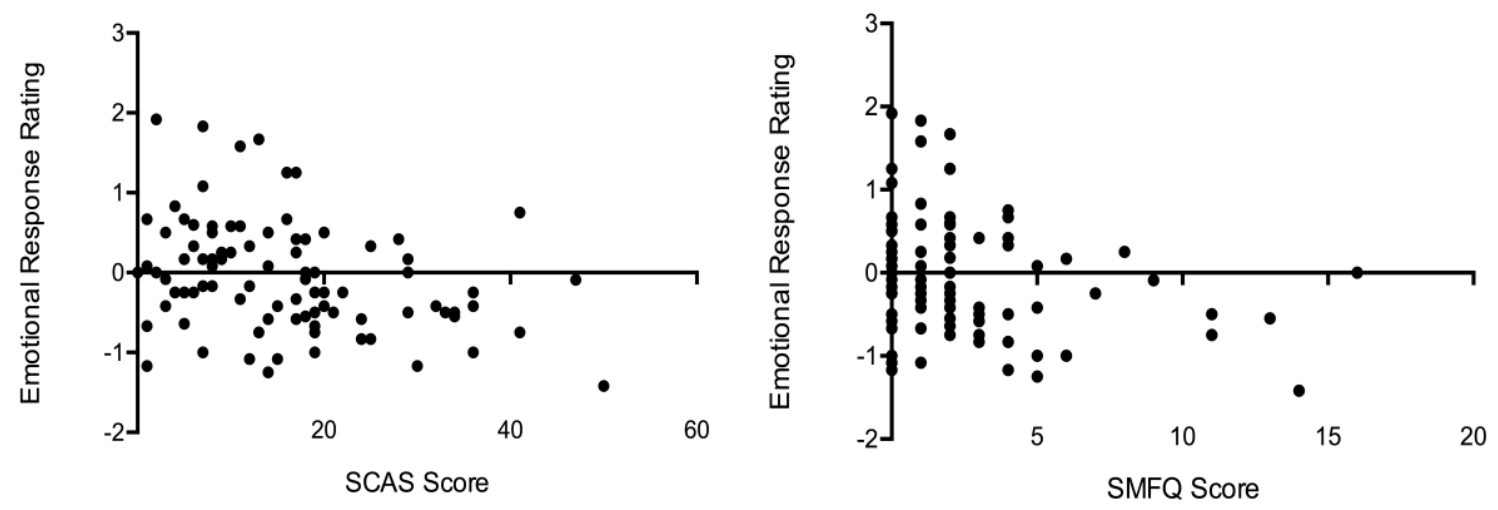

Figure 2. Scatterplots of emotional response ratings with SCAS self-report scores and SMFQ self-report scores respectively. 